\title{
Corticosteroid Use and Periodontal Disease: A Systematic Review
}

\author{
Rebeca Brasil-Oliveira ${ }^{1}$ Álvaro A. Cruz ${ }^{1,2}$ Viviane Almeida Sarmento ${ }^{3}$ Adelmir Souza-Machado ${ }^{1,2}$ \\ Liliane Lins-Kusterer ${ }^{1}$
}

${ }_{1}^{1}$ Postgraduate Program in Medicine and Health, School of Medicine, Federal University of Bahia, Salvador, Bahia, Brazil

${ }^{2}$ ProAR, School of Medicine, Federal University of Bahia, Salvador, Bahia, Brazil

${ }^{3}$ School of Dentistry, Federal University of Bahia, Salvador,

Bahia, Brazil

Address for correspondence Liliane Lins-Kusterer, PhD, School of Medicine, Federal University of Bahia, Salvador, Bahia 400260-10, Brazil (e-mail: liliane.lins@ufba.br).

Eur J Dent:2020;14:496-501

\begin{abstract}
\section{Keywords}

- periodontal disease

- corticosteroid

- review
\end{abstract}

Periodontitis affects the teeth supporting structures, such as periodontal tissues. We aimed to evaluate the association between periodontal disease and corticosteroid use. We searched in MEDLINE, Web of Sciences, SCOPUS, LILACS, and Cochrane databases, using the descriptors "Periodontal diseases" AND ("adrenal cortex hormones" OR "adrenal cortex hormones" OR ("adrenal” AND "cortex" AND "hormones") OR "adrenal cortex hormones" OR "corticosteroid"). We selected the summaries of observational studies, addressing periodontal disease in patients using corticosteroids. The search resulted in 403 articles. After applying the selection criteria, eight studies remained; being two retrospective cohorts and six cross-sectional studies. There are few studies with appropriate methodology to produce sound evidence about the causal relationship between the use of corticosteroids and periodontitis. However, two retrospective cohorts confirmed that chronic corticosteroid use is associated with the incidence of periodontal disease. Dental staff must be aware of this association for better management of periodontal disease therapy in patients using corticosteroids.

\section{Introduction}

Periodontitis, the leading cause of tooth loss in adults, is a disease that affects the teeth supporting structures, such as periodontal tissues. Periodontal disease results in an extension of the inflammatory process initiated by the supporting periodontal tissue, which characterized by inflammation of the gums, presence of subgingival pathogenic plaque, loss of clinical insertion with the presence of periodontal pocket due to injury of the periodontal ligament, and loss of adjacent supporting bone. ${ }^{1}$ Therefore, we understand that periodontitis is a multifactorial disease.

Patients with systemic diseases present physiologic changes triggered by the disease mechanism or by the use of medication, which may contribute to periodontal disease progression. Corticosteroids, for example, are potent steroidal agents that have anti-inflammatory and immunosuppressive action due to different factors. The use of corticosteroids stabilizes the effect on the lysosome membrane, inhibits the production of cytokines that cause vasodilation, increases capillary permeability, inhibits the proliferation of fibroblasts, and reduces collagen production. ${ }^{2}$ Corticosteroids also favor osteoclastogenesis, which leads to increased bone reabsorption and stimulation of the inflammatory process in the periodontal support structure. ${ }^{3}$

Since the introduction of glucocorticoids use in $1940,{ }^{4}$ this class of drugs has been widely prescribed for many medical disorders such as the necessity of replacement therapy in patients with insufficiency of the adrenal gland, in case of immunosuppressive therapy, and also for anti-inflammatory treatment. ${ }^{5}$ The use of corticosteroids in dentistry mainly comprises the control of postoperative edema, the management of oral lesion associated with pemphigus, pemphigoid, lichen planus, erythema multiforme, recurrent aphthous stomatitis, among others, and allergic reactions. ${ }^{6}$ Systemic 
administration in dentistry is necessary in case of extensive trauma or lesion with aggressive symptomatology. ${ }^{6}$

Chronical use of corticosteroids may lead not only to systemic disorders like immunosuppression, suppression of adrenal, hyperglycemia, central obesity, loss of bone mineral density, and osteoporosis, ${ }^{7}$ but also may predispose to oropharyngeal candidiasis and alveolar bone loss. ${ }^{8}$ The association of periodontal disease and the use of corticosteroids is unclear in the scientific literature since periodontal diseases have slow chronic progression, requiring longer follow-up period ${ }^{9}$ and the reports described different methods of intraoral clinical evaluation for diagnosis of periodontal diseases. ${ }^{10,11}$

The purpose of this review was to evaluate the association between periodontal disease and the use of corticosteroids.

\section{Materials and Methods}

The present systematic literature review followed a predefined protocol based on the Preferred Reporting Items for Systematic Reviews guidelines. ${ }^{12}$ This research study protocol has been registered on PROSPERO platform with the number CRD42020164063. We performed a literature searches in MEDLINE (http:// www.ncbi.nlm.nih.gov/pubmed/clinical), Web of Sciences (www.isiknowledge.com), SCOPUS (https:// www.scopus.com/home.uri), LILACS (http://lilacs.bvsalud. org), and Cochrane (http://www.thecochranelibrary.com) databases, using the following descriptors "periodontal diseases" AND ("adrenal cortex hormones" OR "adrenal cortex hormones" OR ("adrenal" AND "cortex" AND "hormones") OR "adrenal cortex hormones" OR "corticosteroid"), from May 2018 to January 2020.

We used the strategy according to Participants, Exposure, Comparisons, Outcomes and Study Designs to develop our research question, considering $\mathrm{P}$ (the population using corticosteroids), E (using corticosteroids), C (having or not having periodontal disease), $\mathrm{O}$ (periodontal disease), and S (observational studies). The following inclusion criteria were applied: cohort, case-control studies, and cross-sectional studies, without time and language restrictions, which investigated the association of periodontal disease and the use of corticosteroids in patients with 18 years or more. Review articles, clinical trials, case reports, editorial letter, and experimental studies with animals were excluded.

Two independent authors performed database searches and read the titles and abstracts of the retrieved articles applying the inclusion and exclusion criteria. Disagreements were sorted out by consensus or by a third reviewer that also validated data extraction. Data were collected about study design, year, country, the methods used to evaluate the presence of periodontal disease, number of patients, mean age, and comorbidities associated with corticosteroid use. All articles analyzed through the abstracts had their eligibility confirmed by the authors accessing the detailed reading of the full text. When any disagreement between the reviewers occurred, they resolved it by consensus.

\section{Results}

We identified 403 articles from MEDLINE (137), Web of Sciences (32), ELSEVIER (227), LILACS (1), and Cochrane (6) databases. We excluded 57 duplicated articles, and other 180 according to the inclusion criteria. Among the latter studies, 129 did not evaluate the use of corticosteroids, 25 were experimental studies with animals, and 4 studies evaluated individuals with age under 18 years. Therefore, eight articles met the inclusion criteria of the proposed review ( - Fig. 1).

All articles included ${ }^{9,13-19}$ were organized in a table, including the two cohort studies and six cross-sectional studies. All eight articles included were written in English. The studies were conducted in Taiwan, ${ }^{9,13}$ India, ${ }^{14}$ Turkey, ${ }^{15,16,18}$ Egypt, ${ }^{17}$ and England. ${ }^{19}$ The associated comorbidities that led to the use of corticosteroids included asthma, ${ }^{9}$ chronic obstructive pulmonary disease (COPD), ${ }^{13,14,18}$ rheumatoid arthritis (RA), ${ }^{15-}$ 17 and renal transplant patients. ${ }^{19}$ The studies included a total of 41,768 individuals with different comorbidities who used corticosteroids and 120,818 individuals in the control groups. Studies have similar mean ages when compared with case and control groups in each study ( - Table $\mathbf{1}$ ).

Cohort studies by Shen et $\mathrm{al}^{9}$ and Shen et $\mathrm{al}^{13}$ reported that individuals with asthma and COPD had higher incidence of periodontal disease when compared with the control group (-Table 2). The incidence of periodontal diseases was 1.18-fold greater (95\% confidence interval [CI]: 1.14-1.22) in the asthma group than in the control group (38.6 vs. 32.5 per 1,000 person-years, respectively), adjusting for sex, age, income, and comorbidities. ${ }^{9}$ Among asthmatic patients, individuals treated with inhaled corticosteroids presented a greater risk of periodontal diseases compared with noncorticosteroid users (adjusted hazard ratios of 1.12 [95\% CI: 1.03-1.23]). Individuals with COPD presented an incidence of periodontal disease 1.20 -fold greater than in the comparison control group (32.2 vs. 26.4 per 1,000 person-years; ( $95 \%$ CI: $1.15-1.24) .^{13}$ Individuals who received corticosteroids as treatment, inhaled corticosteroids (hazard ratio [HR]: 1.22, 95\% CI: $1.11-1.34$ ) or systemic corticosteroids (HR: 1.15 , 95\% CI: 1.07-1.23), showed a higher risk of periodontal diseases when compared with patients that did not receive treatment with corticosteroids. ${ }^{13}$

Cross-sectional studies ${ }^{14,19}$ considered the diagnosis of periodontal disease based on the mean and standard deviation of different intraoral clinical parameters, comparing individuals with different comorbidities who used corticosteroids and individuals in the control group (-Table 3 ).

When assessing plaque index and probing depth, the studies by Biyikoğlu et al ${ }^{15}$ and Biyikoğlu et al ${ }^{16}$ statistically presented higher means in the RA groups compared with the control group, in contrast to the studies by Komerik et $\mathrm{al}^{18}$ and Sutton and Smales et al ${ }^{19}$ present values in which there was no statistical difference between the groups with COPD and kidney transplant and their control groups, respectively (-Table 3).

When assessing the clinical insertion level, we observed that in the groups with $\mathrm{RA},{ }^{15-17}$ there was a greater loss of clinical insertion with statistical significance when 

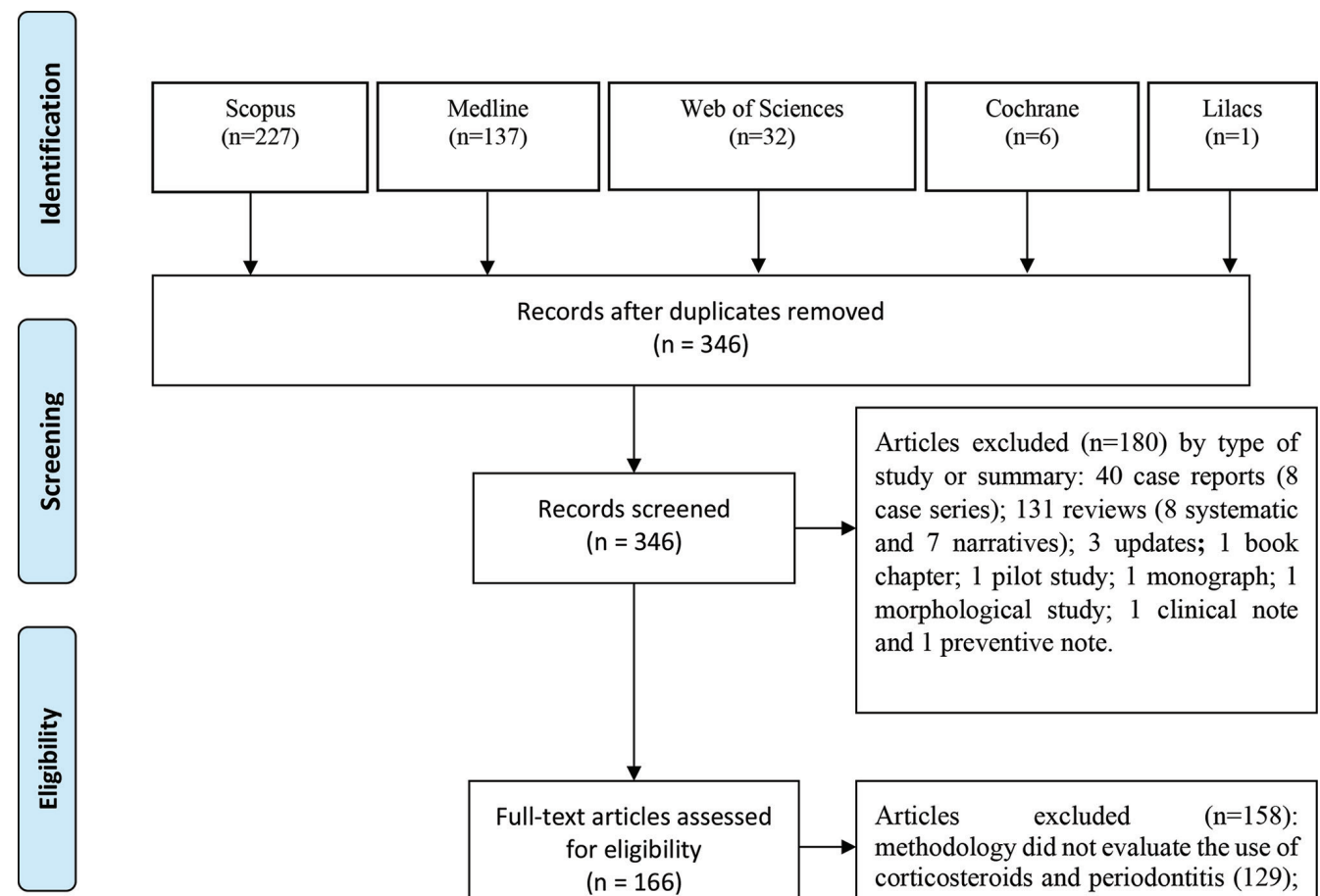

Full-text articles assessed for eligibility ( $n=166)$

Articles excluded $(n=158)$ : methodology did not evaluate the use of corticosteroids and periodontitis (129); performed on animals (25); performed
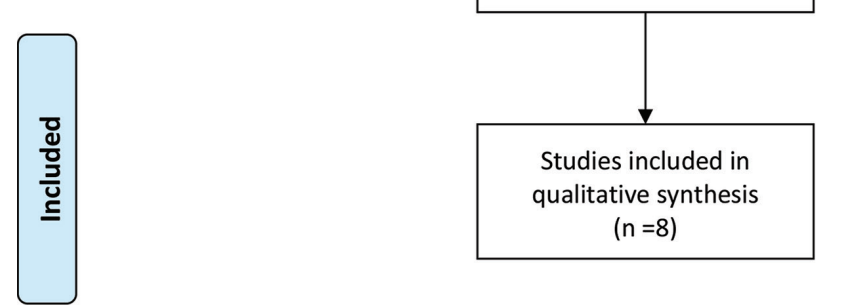
on patients under 18 years old (4);

Fig. 1 Flowchart summarizing the identification and selection of studies.

Table 1 Design and characteristics of included studies

\begin{tabular}{|c|c|c|c|c|c|c|c|c|c|}
\hline Author & Year & Country & Study & Comorbidity & $\begin{array}{l}\text { Cases } \\
(n)\end{array}$ & $\begin{array}{l}\text { Controls } \\
(n)\end{array}$ & $\begin{array}{l}\text { Total } \\
(n)\end{array}$ & $\begin{array}{l}\text { Age of cases } \\
(\text { mean } \pm S D)\end{array}$ & $\begin{array}{l}\text { Age of } \\
\text { controls } \\
\text { (mean } \pm S D \text { ) }\end{array}$ \\
\hline Shen et $\mathrm{al}^{9}$ & 2017 & Taiwan & $\begin{array}{l}\text { Retrospective } \\
\text { cohort }\end{array}$ & Asthma & 19,206 & 76,824 & 96,030 & $41.5 \pm 25.9$ & $41.3 \pm 25.7$ \\
\hline Shen et $\mathrm{al}^{13}$ & 2015 & Taiwan & $\begin{array}{l}\text { Retrospective } \\
\text { cohort }\end{array}$ & COPD & 22,332 & 43,762 & 66,094 & $63.9 \pm 15.9$ & $62.8 \pm 15.7$ \\
\hline Raj et al ${ }^{14}$ & 2018 & India & Cross-sectional & COPD & 170 & 170 & 340 & $36.8 \pm 7.1$ & $35.8 \pm 7.3$ \\
\hline Biyikoğlu et al'15 & 2009 & Turkey & Cross-sectional & Rheumatoid arthritis & 25 & 24 & 49 & $53.7 \pm 0.17$ & $49.1 \pm 6.6$ \\
\hline Biyikoğlu et al ${ }^{16}$ & 2006 & Turkey & Cross-sectional & Rheumatoid arthritis & 23 & 17 & 40 & $52.6 \pm 9.9$ & $40.6 \pm 6.7$ \\
\hline Abou-Raya et al ${ }^{17}$ & 2005 & Egypt & Cross-sectional & Rheumatoid arthritis & 50 & 50 & 100 & $48.0 \pm 10.8$ & $49.4 \pm 10.5$ \\
\hline Kömerik et al ${ }^{18}$ & 2005 & Turkey & Cross-sectional & COPD & 30 & 30 & 60 & $65.9 \pm 11.0$ & $66.2 \pm 8.4$ \\
\hline Sutton et al ${ }^{19}$ & 1983 & England & Cross-sectional & Kidney transplant & 102 & 111 & 213 & $38.7 \pm 1.16$ & $36.2 \pm 1.4$ \\
\hline Total & & & & & 41,938 & 120,988 & 162,926 & & \\
\hline
\end{tabular}

Abbreviations: COPD, chronic obstructive pulmonary disease; SD, standard deviation.

Table 2 Incidence of periodontal disease in the cohort studies

\begin{tabular}{|l|l|l|l|l|l|}
\hline Study $(\mathrm{y})$ & Comorbidity & $\begin{array}{l}\text { PD among cases } \\
(\%)\end{array}$ & $\begin{array}{l}\text { PD among controls } \\
(\%)\end{array}$ & aHR & $\mathbf{9 5 \%} \mathrm{Cl}$ \\
\hline Shen et $\mathrm{al}^{9}(2017)$ & Asthma & 38.6 & 32.5 & 1.18 & $1.14-1.22$ \\
\hline Shen et $\mathrm{al}^{13}(2015)$ & COPD & 32.2 & 26.4 & 1.20 & $1.15-1.25$ \\
\hline
\end{tabular}

Abbreviations: aHR, adjusted hazard ratio; $\mathrm{Cl}$, confidence interval; COPD, chronic obstructive pulmonary disease; PD, periodontal disease. 


\begin{tabular}{|c|c|c|c|c|c|c|}
\hline 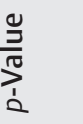 & & $\begin{array}{l}\text { L } \\
\dot{0} \\
\mathrm{v}\end{array}$ & $\begin{array}{l}\stackrel{2}{0} \\
\stackrel{0}{0}\end{array}$ & $\begin{array}{l}\overline{8} \\
\dot{0} \\
\dot{v}\end{array}$ & & $\begin{array}{l}\overline{8} \\
\dot{0} \\
\dot{v}\end{array}$ \\
\hline ర্ৰ ঐ & & $\begin{array}{l}+ \\
+ \\
+1 \\
i \\
\infty\end{array}$ & 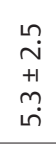 & & & $\begin{array}{l}-\dot{0} \\
+1 \\
\text { ஸn } \\
0\end{array}$ \\
\hline 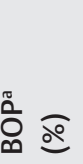 & & $\begin{array}{l}0 \\
\text { N } \\
\text { ñ } \\
+1 \\
0 \\
\stackrel{0}{R}\end{array}$ & $\begin{array}{l}0 \\
\stackrel{D}{N} \\
+1 \\
0 \\
\dot{n}\end{array}$ & & & $\begin{array}{l}- \\
0 \\
+1 \\
+1 \\
0 \\
0\end{array}$ \\
\hline 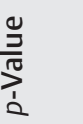 & & $\begin{array}{l}\text { L } \\
\stackrel{0}{0} \\
\dot{v}\end{array}$ & $\begin{array}{l}\text { 号 } \\
\stackrel{0}{\mathrm{v}}\end{array}$ & $\begin{array}{l}\overline{8} \\
\dot{0} \\
\dot{v}\end{array}$ & & \\
\hline & & $\begin{array}{l}\hat{0} \\
0 \\
+1 \\
+ \\
0\end{array}$ & $\begin{array}{l}\hat{0} \\
0 \\
+1 \\
+ \\
0\end{array}$ & & & \\
\hline & & $\begin{array}{l}\infty \\
0 \\
+1 \\
\stackrel{+}{n} \\
\sim\end{array}$ & $\begin{array}{l}n \\
0 \\
0 \\
+1 \\
b \\
\dot{N}\end{array}$ & & & \\
\hline 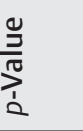 & & $\begin{array}{l}\stackrel{2}{0} \\
\stackrel{0}{0}\end{array}$ & $\begin{array}{l}\stackrel{n}{0} \\
\stackrel{0}{\mathrm{v}}\end{array}$ & $\begin{array}{l}\bar{\delta} \\
\dot{0} \\
\dot{v}\end{array}$ & $\begin{array}{l}\text { Ln } \\
0 \\
\stackrel{\Lambda}{\Lambda}\end{array}$ & $\begin{array}{l}\text { Ln } \\
0 \\
\dot{1}\end{array}$ \\
\hline 住 & & $\begin{array}{l}\tilde{N} \\
0 \\
+1 \\
\stackrel{+}{r}\end{array}$ & $\begin{array}{l}m \\
0 \\
+1 \\
m \\
r\end{array}$ & & $\begin{array}{l}\hat{0} \\
\dot{0} \\
+1 \\
\tilde{n}\end{array}$ & $\begin{array}{l}\overrightarrow{0} \\
+1 \\
\stackrel{+}{N}\end{array}$ \\
\hline$\stackrel{\widehat{E}}{\underline{\underline{E}}}$ & & $\begin{array}{l}0 \\
\dot{0} \\
+1 \\
\stackrel{+}{N}\end{array}$ & $\begin{array}{l}\stackrel{n}{0} \\
\text { +1 } \\
\stackrel{n}{N}\end{array}$ & & $\begin{array}{l}\stackrel{9}{0} \\
+1 \\
+ \\
\dot{m}\end{array}$ & $\begin{array}{l}\overline{0} \\
++1 \\
\text { N } \\
N\end{array}$ \\
\hline 竞 & $\begin{array}{l}\bar{\delta} \\
\dot{\theta} \\
\dot{v}\end{array}$ & $\begin{array}{l}\text { L } \\
\stackrel{0}{\mathrm{v}} \\
\mathrm{v}\end{array}$ & $\begin{array}{l}\stackrel{n}{0} \\
\stackrel{0}{v}\end{array}$ & & $\begin{array}{l}\stackrel{n}{0} \\
0 \\
0 \\
\Lambda\end{array}$ & $\begin{array}{l}\text { Ln } \\
0 \\
\dot{1}\end{array}$ \\
\hline$\frac{0}{\alpha} \widehat{\varrho}$ & $\begin{array}{l}\text { ก) } \\
0 \\
0 \\
+1 \\
0 \\
0 \\
0\end{array}$ & $\begin{array}{l}0 \\
0 \\
+1 \\
0 \\
\dot{1} \\
\end{array}$ & $\begin{array}{l}\stackrel{\llcorner}{\Sigma} \\
\check{\Gamma} \\
+1 \\
\tilde{n} \\
\tilde{m}\end{array}$ & & 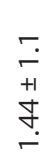 & 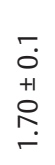 \\
\hline 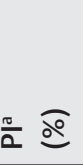 & $\begin{array}{l}\bar{\sigma} \\
0 \\
+1 \\
\text { ó } \\
\dot{\rho} .\end{array}$ & $\begin{array}{l}0 \\
\stackrel{N}{+} \\
+1 \\
0 \\
\dot{\infty} \\
\infty\end{array}$ & $\begin{array}{l}0 \\
\stackrel{1}{+} \\
+1 \\
0 \\
0 \\
\infty\end{array}$ & & $\begin{array}{l}r \\
+ \\
+1 \\
+ \\
+ \\
+ \\
-\end{array}$ & $\begin{array}{l}\overline{0} \\
+1 \\
\infty \\
-\end{array}$ \\
\hline $\begin{array}{l}\overrightarrow{3} \\
\vec{Z} \\
\vec{z}\end{array}$ & 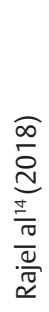 & 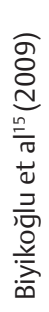 & 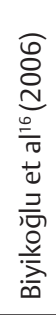 & 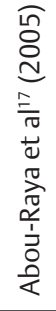 & 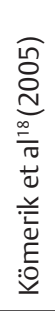 & 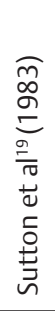 \\
\hline
\end{tabular}

compared with the control groups. And in four studies, ${ }^{15-17,19}$ we observed that the presence of probing bleeding was statistically higher in case groups than in their respective control groups (-Table $\mathbf{3}$ ).

We applied the Newcastle Ottawa Scale (NOS) to evaluate the risk of bias and quality of the included article. The NOS comprises a maximum of nine points for the lowest risk of bias in three domains: the selection of study groups (4 points); group comparability (2 points); and determination of exposure and results ( 3 points). The NOS was chosen to select articles that presented greater transparency in its description, those reaching score 7 were included ${ }^{20}$ (-Table 4).

\section{Discussion}

We have observed that few studies evaluated the effect of corticosteroids on the development and progression of periodontal disease. This article addresses the results of eight articles, two cohort, and six cross-sectional studies that could present different answers to our question.

One cohort study confirmed that asthmatic patients treated with inhaled corticosteroids had a higher risk of periodontal disease than asthmatic patients without corticosteroid treatment. ${ }^{9}$ Another well-conducted cohort study ${ }^{13}$ showed that inhaled or systemic corticosteroids can have a significant effect on the development of periodontal diseases in COPD patients.

In the studies by Biyikoğlu et al ${ }^{15}$ and Biyikoğlu et al, ${ }^{16}$ the coexistence of rheumatoid arthritis and periodontitis affected the measurement of clinical parameters investigated. The study by Abou-Raya et $\mathrm{a}^{14}$ presented data indicating that patients with RA are more likely to have periodontal disease, including more gingival bleeding, presence of dental calculus, alveolar bone loss, when compared with patients without RA. Because periodontal disease and RA have very similar pathologies, a better understanding of the biological processes common to both diseases can help to find new ways to treat them with drugs that modify the body's response to inflammation. ${ }^{14}$

The study by Komerik et $\mathrm{a}^{18}$ suggested that long-term inhaled corticosteroid treatment may impair bone metabolism, leading to a considerable decrease in bone mineral density. However, the cross-sectional study design presents limitation for further conclusions. In addition, it is still difficult to establish the association between prolonged use of inhaled corticosteroids and tooth loss or periodontal disease in COPD patients.

We also found a study in which the results showed statistically significant differences between immunosuppressed patients and controls, using probing depth estimates. However, the authors state that these estimates have no clinical significance due to the higher prevalence of gingival recession in patients treated with corticosteroids. ${ }^{19}$

One study reported that periodontal disease severity was lower among cases compared with controls although caries, plaque, calculus, and candida presence were higher among the cases. It reinforces the need to focus attention on the 
Table 4 Evaluation of quality of included studies by Newcastle-Ottawa scale

\begin{tabular}{|c|c|c|c|c|c|c|c|c|c|}
\hline Study $(y)$ & & $n(<$ & & & Comparability (2) & Exp & (3) & & Total (0-9) \\
\hline Shen et $\mathrm{al}^{9}$ (2017) & $*$ & & 安 & & मे मे & th & मे & मे & 7 \\
\hline Shen et al ${ }^{13}$ (2015) & मे & मे & 支 & & मे & मे & मे & मे & 8 \\
\hline Rajet al ${ }^{14}(2018)$ & मे & मे & 支 & मे & में मे & मे & & & 7 \\
\hline Biyikog`lu et al' ${ }^{15}$ (2009) & मे & मे & 支 & 支 & में मे & मे & 光 & & 8 \\
\hline Biyikog`lu et al ${ }^{16}$ (2006) & मे & मै & 光 & 文 & मे मे & मे & मे & & 8 \\
\hline Abou-Raya et al' ${ }^{17}$ (2005) & मे & मे & मे & मे & मे मे & 安 & & & 7 \\
\hline Kömerik et al' ${ }^{18}$ (2005) & मे & मे & मे & मे & मे मे & मे & मे & & 8 \\
\hline Sutton et al ${ }^{19}(1983)$ & मे & मे & & 支 & में मे & मे & मे & & 7 \\
\hline
\end{tabular}

effects of COPD medication on the oral health status of adults and on the need to develop oral hygiene protocols during therapy. ${ }^{14}$

The study by Fabbri et $\mathrm{al}^{21}$ shows us that the treatment of periodontal disease can have a beneficial effect on the management of SLE patients on immunosuppressive therapy and that the management of this modifiable risk factor is highly recommended.

One study reported that corticosteroid therapy maintained over 1 to 4 years has no influence on the development of gingival or periodontal disease in patients with multiple sclerosis. ${ }^{22}$

This study has some limitations that may affect the validity of the conclusions, including the inclusion of studies with clinical heterogeneity and the inclusion of cross-sectional studies, which assesses oral health parameters in one moment only. To reduce the bias of results, we only included studies that had diagnostic evidence of periodontal disease and that all patients in the group if using corticosteroids.

Many risk factors can influence the individual's response to the onset and progression of periodontal disease. Since it is a multifactorial disease, the metabolism of some systemic diseases, tooth loss, loss of the level of clinical insertion, ${ }^{23,24}$ poor oral hygiene, ${ }^{25}$ obesity, smoking, ${ }^{24}$ genetics, immune response, stress, anxiety, and depression ${ }^{26}$ may be responsible for making the host more susceptible to immunoinflammatory changes in periodontal disease. Therefore, not taking into consideration, these risk factors could have biased the results of this review.

The eight studies also differed about many methodological aspects: selection criteria of patients in each group, the type of corticosteroid administered in therapy, the techniques used to evaluate periodontal disease in intraoral examinations, external variables such as school and economic level of the studied population, and data from different countries. This heterogeneity is evidenced in the presentation of the results of the clinical parameters analyzed in each study. Thus, it is important to conduct further studies about a putative cause-effect relationship of corticosteroid use and periodontal disease.

This study has some limitations as the heterogeneity of underlying diseases, and the lack of information about comorbidities. The lack of assessment of the total daily or cumulative dose of inhaled, oral, and/or parenteral corticosteroids use limits our conclusions. Missing data about oral hygiene supervision and oral care in patients using the medication also represents a limitation. Literature is scarce of studies with representative samples and adequate methodology, which could address the epidemiological aspects involved in the association between periodontitis and the use of corticosteroids since both conditions present similarities in the inflammatory mechanisms. The effect of the use of corticosteroids on oral biofilm, salivary flow, oral microbiota, and immunoglobulins needs to be elucidated.

The present review evidenced that there are few studies with appropriate methodology to produce sound evidence about the causal relationship between the use of corticosteroids and periodontitis. Although the retrospective cohort studies did not establish the strength of the association between COPD or asthma and periodontitis, they confirmed that patients with asthma and COPD treated with corticosteroids presented higher incidence of periodontal disease compared with individuals treated with other drugs. Dental staff must be aware of this association for better management of periodontal disease therapy in patients using corticosteroids, either inhaled or oral.

\section{Funding}

This study was financed in part by the Coordenação de Aperfeiçoamento de Pessoal de Nível Superior-BrasilFinanceCode 001 and Programa de Pós-Graduação em Medicina e Saúde, Faculdade de Medicina da Bahia, Universidade Federal da Bahia, Salvador, Bahia, Brazilandalsoby Conselho Nacional para o Desenvolvimento Científico e Tecnológico (CNPq), grant 471057/2014-2, Fundação de Amparo à Pesquisa do Estado da Bahia.

\section{Conflict of Interest}

None declared.

\section{Reference}

1 Newman MG, Calmes R, Periodontal disease. Oral Biology. St Louis: CV Mosby Co.; 1981;369

2 Valente O, Atallah AN. Efeitos metabólicos e manuseio clínico dos corticosteróides. Atualizaçäo terapêutica: manual prático de diagnóstico e tratamento. São Paulo. Art Med 2003;21: $1710-1712$

3 Canalis E, Mazziotti G, Giustina A, Bilezikian JP. Glucocorticoidinduced osteoporosis: pathophysiology and therapy. Osteoporos Int 2007;18(10):1319-1328 
4 Benedek TG. History of the development of corticosteroid therapy. Clin Exp Rheumatol 2011;29(5Suppl 68):S5-S12

5 Bennett PN, Brown MJ, Clinical Pharmacology. 9th ed. New Delhi: Reed Elsevier; 2003 ; 664

6 Hargitai LI, Sherman CR. Corticosteroids in dentistry. Clin Update 2001;23:11-12

7 Yasir M, Goyal A, Bansal P, Sonthalia S, StatPearls. Corticosteroid Adverse Effects. Treasure Island (FL): StatPearls Publishing; 2020

8 Tripathi KD, Essentials of Medical Pharmacology. 6th ed. New Delhi: Jaypee Brothers Medical Publishers (P) Ltd; 2008

9 Shen TC, Chang PY, Lin CL, et al. Risk of periodontal disease in patients with asthma: a nationwide population-based retrospective cohort study. J Periodontol 2017; 88(8):723-730

10 Page RC, Eke PI. Case definitions for use in population-based surveillance of periodontitis. J Periodontol 2007;78:1387-1399

11 Leroy R, Eaton KA, Savage A. Methodological issues in epidemiological studies of periodontitis-how can it be improved? BMC Oral Health 2010;10:8

12 Preferred Reporting Items for Systematic Reviews and MetaAnalyses. The PRISMA Statement. Disponívelem: Available at: www.prisma-statement.org. Accessed May 27, 2020

13 Shen TC, Chang PY, Lin CL, et al. Risk of periodontal diseases in patients with chronic obstructive pulmonary disease: a nationwide population-based cohort study. Medicine (Baltimore) 2015; 94(46):e2047

14 Raj R, Manu MK, Prakash PY, Singhal DK, Acharya S. The effect of 6 months or longer duration of chronic obstructive respiratory disease medication on the oral health parameters of adults. Spec Care Dentist 2018; 38(3):133-138

15 Biyikoğlu B, Buduneli N, Kardeşler L, Aksu K, Pitkala M, Sorsa T. Gingival crevicular fluid MMP-8 and -13 and TIMP-1 levels in patients with rheumatoid arthritis and inflammatory periodontal disease. J Periodontol 2009; 80(8):1307-1314

16 Biyikoğlu B, Buduneli N, Kardeşler L, Aksu K, Oder G, Kütükçüler N. Evaluation of t-PA, PAI-2, IL-1beta and PGE(2) in gingival crevicular fluid of rheumatoid arthritis patients with periodontal disease. J Clin Periodontol 2006; 33(9):605-611

17 Abou-Raya A, Abou-Raya S, Abu-Elkheir H. Periodontal disease and rheumatoid arthritis: is there a link? Scand J Rheumatol 2005;34(5):408-410

18 Komerik N, Akkaya A, Yildiz M, Buyukkaplan US, Kuru L. Oral health in patients on inhaled corticosteroid treatment. Oral Dis 2005;11(5):303-308

19 Sutton RBO, Smales FC. Cross-sectional study of the effects of immunosuppressive drugs on chronic periodontal disease in man. J Clin Periodontol 1983;10(3):317-326

20 Wells GA, Shea B, O'Çonnell D, Peterson J, Welch V, Losos Metal. The Newcastle-Ottawa Sacale (NOS) for assessing the quality of nonrandomized studies in meta-analyses. 2014. Available at: http://www.ohri.ca/programs/clinical_epidemiology/oxford.asp. Accessed May 27, 2020

21 Fabbri C, Fuller R, Bonfá E, Guedes LKN, D’Alleva PSR, Borba EF. Periodontitis treatment improves systemic lupus erythematosus response to immunosuppressive therapy. Clin Rheumatol 2014;33(4):505-509

22 Safkan B, Knuuttila M. Corticosteroid therapy and periodontal disease. J Clin Periodontol 1984;11(8):515-522

23 Lima TR, Costa LS, Cruz Neto ES, Mesquita NB, Brito LF, Silveira VRS. Perda dentária e doença periodontal associada ou não a condições sistêmicas revisão de literatura. Periodontia. 2019; 29(2):3-42

24 Moghadam SA, Shirzaiy M, Risbaf S. The association between periodontitis and respiratory disease. J Nepal Health Res Counc 2017; 15(1):1-6

25 Lertpimonchai A, Rattanasiri S, Arj-Ong Vallibhakara S, Attia J, Thakkinstian A. The association between oral hygiene and periodontitis: a systematic review and meta-analysis. Int Dent J 2017; 67(6):332-343

26 Dantas FT, Martins SHL, Dantas ATM, Gnoatto N. Stress and periodontal disease: a literature review. Periodontia. 2016; 26(3):19-28 